\title{
"Today I felt like my work meant something": A pilot study on job crafting, a coaching-based intervention for people with work limitations and disabilities
}

\author{
Vidya Sundar ${ }^{\mathrm{a}, *}$ and Debra Brucker ${ }^{\mathrm{b}}$ \\ ${ }^{a}$ Occupational Therapy Department, University of New Hampshire, Durham, NH, USA \\ ${ }^{\mathrm{b}}$ Institute on Disability, University of New Hampshire, Durham, NH, USA
}

Received 24 June 2019

Accepted 29 August 2020

\begin{abstract}
.
BACKGROUND: People's work life and career can ultimately be deconstructed to the day-to-day job tasks they perform, the people they interact with, and the value and meaning attached to their jobs. Individuals with work limitations and disabilities consistently experience disparities in the workplace resulting in a less than optimal work experience in all three areas.

OBJECTIVE: The purpose of this study is to conduct a pilot study to test the effectiveness of job crafting as an occupational therapy (OT) intervention strategy for workers with health conditions and impairments. Job crafting is a proactive, strengthsbased, bottom-up approach where workers renegotiate and redefine their job tasks in a personally meaningful way.

METHODS: A mixed-methods study $(n=11)$ was conducted with workers who experience work limitations and disabilities. OT graduate students conducted in-depth interviews and facilitated the use of job crafting to improve work-related outcomes. Pre-and post-intervention data was analyzed using descriptive statistics and Wilcoxon signed-rank tests. Qualitative data was transcribed, coded, and synthesized.

RESULTS: The job crafting intervention improved work-related self-efficacy $(p<0.05)$ and crafting behaviors $(p<0.05)$ in the workplace. Participants accomplished goals to manage their work limitations, meet job demands, and other non-disability related challenges.

CONCLUSIONS: Job crafting has the potential to be used as a holistic OT intervention strategy to improve work-related self-efficacy among workers with work limitations and disabilities
\end{abstract}

Keywords: Employment, workplace, disabled persons, self-efficacy, work engagement, coaching

\section{Introduction}

"Today I felt like my work meant something, but not so much on other days" - Susan, Elementary school teacher

\footnotetext{
*Address for correspondence: Vidya Sundar, PhD, OTR/L, Assistant Professor, Occupational Therapy Department, University of New Hampshire, 4 Library Way, Durham, NH - 03824, USA. Tel.: +1 603862 0284; E-mail: vidya.sundar@unh.edu.
}

"[I] had a good productive day and accomplished much. [I] have found a good balance of physical work and paperwork" - Mike, Information technology professional

Susan and Mike, both employees with health conditions and work limitations, were reflecting on their work performance and the value and meaning of their work after participating in a research study on job 
crafting. Susan experienced generalized anxiety disorder, occasional panic attacks, and low self-esteem, which impacted her ability to be an assertive and self-directed lead teacher. Mike experienced shoulder bursitis with an impinged nerve, knee pain and generalized anxiety and was finding it increasingly difficult to do some of the physical tasks required of his information technology job. Susan and Mike were among 11 individuals with work limitations who recently participated in a pilot study on using job crafting as an occupational therapy (OT) intervention to improve work-related outcomes. Job crafting is a novel, coaching-based intervention which has been found to be effective in assisting employees to manage their careers by negotiating and crafting job tasks to suit their unique needs, skills, and values [1,2]. We hypothesize that job crafting has the potential to be used as an OT intervention to assist workers with work limitations and disabilities remain gainfully engaged in the workforce by increasing levels of occupational self-efficacy and work engagement. The purpose of the study is to test the effectiveness of using job crafting as an OT intervention to improve work related outcomes among individuals with work limitations and disabilities that may result from a health or chronic condition.

\section{Background}

Individuals with work limitations and disabilities experience consistently lower rate of employment [3] and underemployment [4] compared to those without disabilities. Underemployment can manifest in the form of working fewer hours than desired, working in a lower paying job or working at a job in which the individual is overqualified. Despite these employment disparities, many individuals with work limitations and disabilities strive to work, overcome barriers in the workplace, and retain their jobs [3]. They do so by actively managing their careers, advocating for themselves, and adapting to work roles for successful integration in the workplace [3-5]. Noonan and colleagues [6] established that women with disabilities managed their careers by persisting in their jobs despite having a disability, by being recognized, and by affecting social change within the organization through day-to-day interactions. Kulkarni and Gopakumar [7] noted that some employees with disabilities utilize targeted strategies and behaviors to demonstrate their competence and self-management skills. Such strategies include having a mind-set of extreme persistence, engaging in disability advocacy, and expanding social networks within the organization. By priming employers and co-workers to perceive their ability rather than disability, demonstrating competence by learning new skills, and seeking honest and periodic feedback from supervisors, people with disabilities are able to thrive and sustain in their jobs $[6,7]$.

\subsection{Job crafting}

Job crafting is the process by which employees take active steps in defining and designing their own job experience in a personally meaningful way [1]. A person's work life and career can be ultimately deconstructed to the day-to-day job tasks they perform, the people they interact with, and the value and meaning they attach to their jobs. While the specific job tasks employees engage in are primarily determined by job descriptions, most employees have some latitude in determining how they perform job tasks. For example, a restaurant manager who is responsible for ordering supplies and stock may choose to do the same online versus via a phone call, depending on his/her personal preference, thus crafting how he/she performs the job. This proactive behavior allows employees to meet their job demands with their unique skill set and preferences.

Job crafting occurs in three primary areas: (1) Task crafting refers to changes in job tasks and how they are performed. Task crafting can happen by employees taking on additional responsibilities, emphasizing certain job tasks or redesigning job tasks [2]. For people with work limitations and disabilities, task crafting can include informal alternate ways of performing a job task, the use of assistive technology, reasonable accommodations, or job redesign. (2) Relational crafting refers to changing the extent or nature of one's interactions with people, within and outside the organization. Relational crafting can happen through building new relationships, reframing existing relationships, and adapting relationships. Relational crafting can also be embedded within task crafting, wherein social interactions are molded within the context of a particular task, thereby altering the way a task is performed [2]. (3) Cognitive crafting involves changing perceptions about one's job or job tasks to enhance meaningfulness [2]. This is a mental or cognitive type of job crafting since it does not involve making any physical or 
social changes but rather involves reshaping of one's thoughts and perceptions about one's job. Cognitive crafting can take the form of expanding perceptions, focusing perceptions, or linking perceptions where people make connections between different aspects of their job tasks to create a meaningful schema.

Job crafting is distinct from other processes and programs that support employment for persons with work limitations and disabilities. For example, supported employment includes the use of job coaches, on-the-job training, job development and other support services to help individuals with work limitations and disabilities be successful in competitive employment $[8,9]$. In comparison, job crafting does not involve job search or job creation strategies and does not rely upon a job coach and long-term supports to negotiate job tasks and duties for a person returning to work. Job crafting instead relies on the employee to navigate these adjustments within an existing workplace. Job crafting differs from approaches such as cognitive behavioral therapy which focus on improving mental and behavioral health through participation in a short number of individual psychotherapy sessions designed to increase the ability to reframe negative emotions or behaviors. Employment is typically not a focus of this approach [10-12]. Last, job crafting differs from the Model of Occupational Self-Efficacy [13, 14], a four-stage OT approach in which occupational therapists assist individuals with traumatic brain injury return to work because job crafting is an employee driven, workplace-based approach to increasing self-efficacy and engagement within an existing job.

\subsection{Relationship between job crafting and occupational self-efficacy and work engagement}

Self-efficacy has a direct relationship with previous and current work skills [15-17]. Self-efficacy relates to "people's judgment of their capabilities to organize and execute courses of action required to attain designated types of performances" [19, p.391]. Several research studies note the utility of self-efficacy in understanding career development and management of individuals with work limitations and disabilities $[15,17]$ and recommend the use of self-efficacy-based constructs in developing and creating interventions to support career interventions for people with disabilities [16, 18]. In a study conducted by Tims and colleagues [20], day-to-day self-efficacy was directly related to crafting, as employees who engaged in job crafting behaviors were more likely to be feeling higher levels of self-efficacy compared to pre-intervention. Daily job crafting behaviors were also directly related to work engagement and performance [21]. Work engagement is a "positive, work-related state of mind in employees characterized by vigor, dedication, and absorption" [22]. Considered together, improving occupational selfefficacy and work engagement through job crafting behaviors can have a positive impact on job performance and career management.

\subsection{Effectiveness of job crafting intervention}

Job crafting as an intervention strategy has been well researched and tested among individuals without disabilities. By increasing social and structural resources within the organization, job crafting was found to be a significant predictor of job satisfaction, work engagement, and occupational self-efficacy [23]. Job crafting is theory-based and has been tested in practice and research to improve work outcomes among individuals without disabilities [24-29]. To the best of our knowledge, there are no published studies with empirical data on job crafting interventions among people with work limitations and disabilities and only three published studies exploring how older adults nearing retirement age craft their jobs [30, 31]. Job crafting as an approach to careerself management is something that many individuals with and without disabilities may utilize on their own, intuitively. Many individuals (with or without work limitations and disabilities) who negotiate challenges at work or move up in their career ladders, may be intrinsically better at crafting their own jobs and charting a successful career pathway. However, a significant number of individuals may need assistance with identifying and implementing such strategies. This is especially true for people with work limitations and disabilities who face multiple personal and structural barriers including low-occupational self-efficacy, stigma, and lack of awareness about employment legislations [3].

\subsection{Potential for job crafting to be used as an OT intervention}

OT interventions in the domain of work rehabilitation are geared towards short-term adaptation through work hardening, injury prevention, or ergonomic solutions $[33,34]$ or long-term adaptation through 
vocational rehabilitation or return to work [35]. An emerging area of practice for occupational therapists is assisting clients in realizing their fullest potential at work [36-38] by improving their job retention and tenure. Coaching-based interventions can be used to facilitate positive work outcomes such as productivity, job satisfaction, and engagement in the workplace [39]. Occupational performance coaching is one example of such an evidence informed coaching-based intervention, where a collaborative model is used to guide clients in the process of problem identification, goal setting, and action planning $[37,39]$. The therapist assumes the role of a facilitator who guides clients in problem-solving rather than direct instruction or education. Conventional coaching sessions used by occupational therapists may be delivered remotely or in a face-to-face setting over several weeks. While coaching-based interventions have been previously tested among families of children with autism and individuals experiencing stroke [36, 40, 41], it has not been tested in the workplace for workers with work limitations and disabilities thus far. A coaching-based intervention that uses job crafting can help clients identify areas of strengths, actively set goals, and empower clients to improve occupational self-efficacy and engagement in the workplace. Occupational therapists have a unique opportunity to facilitate engagement and self-efficacy in the workplace thereby promoting the long-term career success of individuals with work limitations and disabilities. This study, therefore, aims to pilot test the use of such a strategy. We hypothesize that job crafting, used as an occupationbased intervention, can increase self-efficacy, work engagement, organizational citizenship, and crafting behaviors among workers with work limitations and disabilities. Additionally, we seek to understand the process by which individuals with work limitations and disabilities craft their jobs and navigate their work demands.

\section{Methods}

This pilot study was conducted in the United States. A mixed-method, concurrent explanatory design [42] was used. Prior to commencing the study, approval from the Institutional Review Board at the University of New Hampshire was obtained. All participating researchers completed IRB training to ensure ethical treatment of involved participants. Graduate OT students involved in participant recruitment, data collection and analysis were enrolled in a 14-week research engagement course, a graduate course which required that they conduct mentored research. Prior to enrolling in the research engagement course, all students had successfully completed two other required graduate statistics and research courses, providing the training necessary to complete all tasks associated with the pilot study.

Study participants were recruited by graduate OT students. Participants were recruited for the study if they were: (1) 18-64 years old; (2) experienced a physical or mild mental/psychological condition which limited their work performance; (3) worked at least 10 hours a week but were not self-employed; (4) employed for at least 1 year; and (5) able to comprehend English. Subjects were excluded from the study if they had: (1) a primary diagnosis of cognitive or psychiatric disorders; or (2) cognitive limitations that prevented them from providing informed consent. Twelve participants were recruited for the study using a purposive sampling strategy. Purposive sampling was used to ensure that participants represent a wide range of health conditions, work limitations, industries, and work experience.

A mix of quantitative and qualitative data were collected over three phases: (1) pre-intervention online survey phase, (2) two face-to-face sessions to conduct an in-depth interview and complete the Job Crafting Exercise $^{\mathrm{TM}}$, and (3) a goal implementation and postintervention online survey phase. Figure 1 shows the timeline of data collection activities and the type of data collected.

\subsection{Data collection}

During the pre-intervention phase, participants completed an online daily survey for five consecutive workdays to measure their pre-intervention levels of occupational self-efficacy, work engagement, organizational citizenship, and job crafting behaviors. The survey was created in Qualtrics and included standardized questions as well as open-ended questions to capture any out of the ordinary events that may have influenced participants' level of self-efficacy. Questions are listed in Table 1. The questionnaire took 10 minutes or less to complete each day. Questionnaire items were taken from relevant scales including the Occupational Self-Efficacy Scale [43], a modified version of the Utrecht Work Engagement Scale [44], a modified Organizational Citizenship Behavior Scale [45], and the Job Crafting Questionnaire [46] as outlined in research conducted by Tims and 


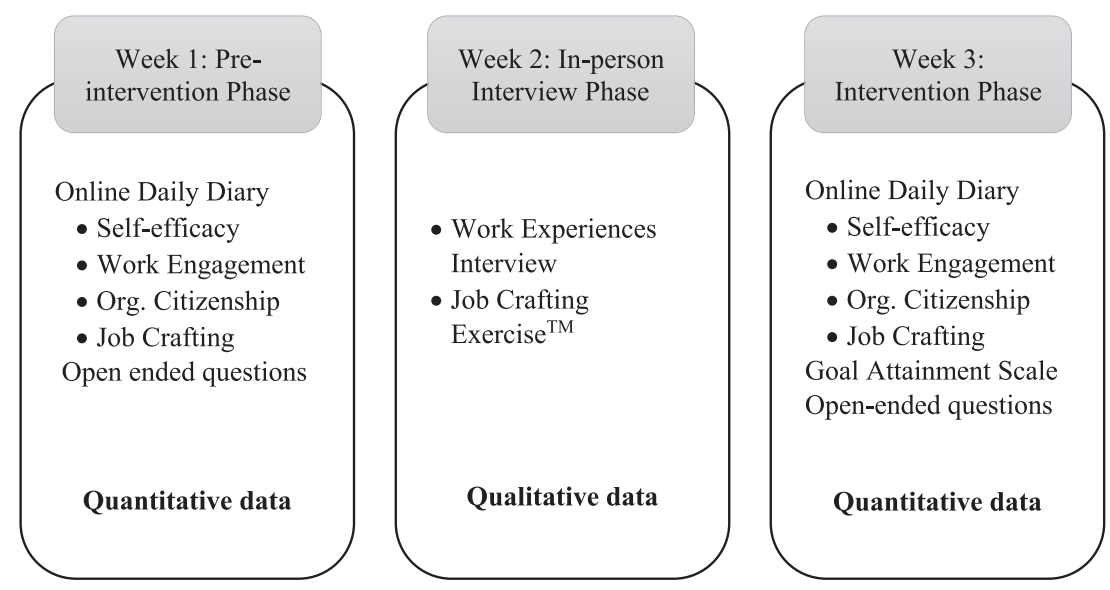

Fig. 1. Study design and data collection.

Table 1

Pre- and post-intervention, online daily diary questions

\begin{tabular}{|c|c|c|}
\hline \multicolumn{3}{|l|}{ Occupational self-efficacy } \\
\hline 1. I can remain calm when facing difficulties in my job because I can rely on my abilities. & 1: Not at all true & 6: Completely true \\
\hline 2. I feel prepared to meet most of the demands in my job. & 1: Not at all true & 6: Completely true \\
\hline 3. I meet the goals that I set for myself in my job. & 1: Not at all true & 6: Completely true \\
\hline \multicolumn{3}{|l|}{ Modified Utrecht Work Engagement Scale } \\
\hline 1. Today, I found the work that I do full of meaning and purpose. & 1: Almost never & 6: Always \\
\hline 2. Today, I was enthusiastic about my job. & 1: Almost never & 6: Always \\
\hline \multicolumn{3}{|l|}{ Modified Organizational Citizenship Scale } \\
\hline 1. Today, I was able to adequately complete assigned duties. & 1: Almost never & 6: Always \\
\hline 2. Today, I had freedom to use my judgment. & 1: Almost never & 6: Always \\
\hline 3. Today, I got a feeling of accomplishment. & 1: Almost never & 6: Always \\
\hline 4. Today, my working conditions are pleasant. & 1: Almost never & 6: Always \\
\hline \multicolumn{3}{|l|}{ Job Crafting Questionnaire } \\
\hline \multicolumn{3}{|l|}{ How often did you } \\
\hline 1. Change minor procedures that you think are not productive. & 1: Hardly ever & 6: Very often \\
\hline 2. Think about the ways in which your work positively impacts your life. & 1: Hardly ever & 6: Very often \\
\hline 3. Remind yourself about the significance your work has for the success of the organization. & 1: Hardly ever & 6: Very often \\
\hline 4. Make an effort to get to know people well at work. & 1: Hardly ever & 6: Very often \\
\hline 5. Meet the goals that I set for myself in my job. & 1: Hardly ever & 6: Very often \\
\hline \multicolumn{3}{|l|}{ Open ended questions } \\
\hline \multicolumn{3}{|l|}{ Pre-intervention phase } \\
\hline \multicolumn{3}{|l|}{ 1. Were there any specific incidents at work that led you to feel the way you did today? Please explain } \\
\hline \multicolumn{3}{|c|}{ Post-intervention phase } \\
\hline \multicolumn{3}{|c|}{ 1. What helped you accomplish $<$ goal1/goal2/goal3 $>$ today? or What kept you from addressing $<$ goal1/goal2/goal3 $>$ today } \\
\hline \multicolumn{3}{|c|}{ 2. What helped you accomplish < goal1/goal $2 /$ goal3 $>$ today? or What kept you from addressing $<$ goal1/goal $2 /$ goal $3>$ today? } \\
\hline \multicolumn{3}{|c|}{ 3. How was the job crafting exercise helpful (or not helpful) in the following three areas? Please explain. } \\
\hline \multicolumn{3}{|l|}{ Goal 1: } \\
\hline \multicolumn{3}{|l|}{ Goal 2: } \\
\hline Goal 3: & & \\
\hline
\end{tabular}

colleagues [47] and other researchers [48, 49]. Daily diary questions are presented in Table 1.

During the intervention phase, participants met face-to-face with graduate OT students over two sessions. In the first session, graduate students conducted a semi-structured interview with participants to understand the nature of their work and to examine how participants constructed their work experience in the context of their disability or health condition. Interview questions focused on participants' job characteristics, task performance, role identity, workplace culture, and role of disability or health condition. The interviews took about 30-40 minutes to complete and were audio recorded and transcribed by the graduate students. Of the twelve participants who completed the pre-intervention interview, one partic- 
ipant refused to have their interview audiotaped. In lieu of audio recordings, extensive field notes were taken during the interview.

In the second face-to-face session, graduate OT students introduced the study participants to the job crafting model using a modified version of the Job Crafting Exercise $^{\mathrm{TM}}$ [50]. The Job Crafting Exercise ${ }^{\mathrm{TM}}$ is an interactive workbook which assists participants in: (1) identifying specific job tasks that participants find challenging or stressful; (2) identifying resources within their organization or personal strategies to address the problem; and, (3) creating an action plan and implementing the plan. The graduate students participated in a collaborative problem-solving process with the participants to identify job tasks and roles that were limited by participants' disability or health condition and to categorize job tasks and roles as time and energy intensive vs. personally meaningful. At the end of the session, students guided participants in developing three short-term goals that the participants would seek to accomplish in the next 1-2 weeks, along with action steps for each goal. The exercise helped participants identify avenues to refine and redefine their job tasks to ones that were more meaningful and engaging for themselves, thereby crafting their own jobs. The workbook exercise generally took 20-30 minutes to complete.

The final implementation phase lasted five consecutive workdays. During this phase, participants actively implemented the goals they had set for themselves and completed the online daily diary at the end of each workday. As mentioned earlier, the daily diary included scales measuring levels of occupational self-efficacy, work engagement, organizational citizenship, and job crafting behaviors as well as open-ended questions designed to capture any out of the ordinary events that may have influenced participants' level of self-efficacy. The post-intervention daily diary included the same questionnaires and scales as the pre-intervention survey, where participants stated their agreement with questions using a Likert scale that ranged from 1 to 6 . In addition, the post-intervention daily diary included a simplified version of the Goal Attainment Scale [51], where each participant rated the extent to which they addressed their goals. Participants were asked to identify whether they: (1) did not address; (2) addressed but did not complete/accomplish; or, (3) accomplished each goal on any given day. A final question asked whether the participants found the Job Crafting Exercise ${ }^{\mathrm{TM}}$ helpful or not in problem solving, facilitating social interactions at work, and reinforcing the meaning and value of work. Participants were compensated a total of $\$ 75.00$ in the form of Amazon gift cards for completing all three phases of the study.

\subsection{Data analysis}

Data was analyzed using the protocol for thematic analysis as recommended by Braun and Clarke [52]. After checking the transcripts for errors and accuracy, graduate students read and reviewed the transcripts to familiarize themselves with the content of the interviews. Initial codes were generated independently by each graduate student and consolidated through a consensus review process over 2-3 sessions. When consensus was not achieved, the graduate faculty mentor (first author) provided input to resolve the discrepancy in coding. The faculty mentor reviewed and verified all coding completed by graduate students. The first author also consolidated and reorganized the first-order codes developed by the students into second-order themes using NVIVO version 12.

For the pre- and post-intervention quantitative data, we averaged scores across the 5 days for each participant for each portion of the study and then used descriptive statistics and Wilcoxon sign-rank tests to evaluate differences in the measured outcomes [53].

\section{Results}

\subsection{Participant characteristics}

Twelve participants agreed to participate in the study; all 12 completed the pre-intervention phase and the Job Crafting Exercise ${ }^{\mathrm{TM}}$ and 11 completed the post-intervention phase of the study. One participant dropped out of the study for reasons unknown. Of the 12 pre-intervention participants, the average age of participants was $34.16(\mathrm{SD}=13.24)$; six were male (46\%); and, 12 (92\%) worked full-time. Participant characteristics are summarized in Table 2. We used pseudonyms to protect the identity of our participants.

\subsection{Pre-intervention daily dairy and reflections}

The pre-intervention survey included brief versions of standardized questionnaires and an openended question on each day's work experience. Overall, pre-intervention average scores $(n=12)$ indicated a high level of self-efficacy $(M=5.00$, 
Table 2

Participant characteristics (Pre-intervention, $N=12$ )

\begin{tabular}{|c|c|c|c|c|}
\hline Name & Gender, age & Job title & $\begin{array}{l}\text { Years in current } \\
\text { position }\end{array}$ & Disability or chronic condition \\
\hline 1. Andy & Male, 24 years old & $\begin{array}{l}\text { Associate Director of } \\
\text { Athletic } \\
\text { Communications }\end{array}$ & 5 years & Attention Deficit Hyperactivity Disorder, low-back pain \\
\hline 2. Mike & Male, 55 years old & $\begin{array}{l}\text { Disaster Recovery } \\
\text { Coordinator }\end{array}$ & 5 years & $\begin{array}{l}\text { Shoulder bursitis and generalized anxiety. } \\
\text { Pain and difficulty with sustained physical activities and } \\
\text { reaching overhead }\end{array}$ \\
\hline 3. Molly & Female, 26 years old & Vegetable Farmer & 1 year & $\begin{array}{l}\text { Repetitive stress injury; pain in thumb, fingers, and } \\
\text { wrist. } \\
\text { Difficulty using hand tools for seeding, hoeing, } \\
\text { transplanting, and harvesting. Difficulty milking cows, } \\
\text { feeding and moving animals }\end{array}$ \\
\hline 4. Susan & Female, 24 years old & $\begin{array}{l}\text { Lead Preschool } \\
\text { Teacher }\end{array}$ & 7 years & $\begin{array}{l}\text { General anxiety and panic disorder. } \\
\text { Difficulty in initiating and taking ownership of job } \\
\text { tasks; difficulty in assuming leadership roles }\end{array}$ \\
\hline 5. Lisa & Female, 49 years old & Finance Director & 17 years & Chronic pain syndrome \\
\hline 6. Jada & Female, 23 years old & $\begin{array}{l}\text { Customer Support and } \\
\text { Services Specialist }\end{array}$ & 10 months & Low back pain \\
\hline 7. Elijah & Male, 24 years old & $\begin{array}{l}\text { Business Systems } \\
\text { Analyst }\end{array}$ & 2.5 years & Chronic back pain, Carpel Tunnel Syndrome \\
\hline 8. Bree & Female, 24 years old & $\begin{array}{l}\text { Customer Service } \\
\text { Representative } \\
\text { Supervisor }\end{array}$ & 1.5 years & $\begin{array}{l}\text { Low back pain. } \\
\text { Difficulty standing for a prolonged time, bending, lifting } \\
\text { heavy objects }\end{array}$ \\
\hline 9. Jackie & Female, 30 years old & $\begin{array}{l}\text { Elementary school } \\
\text { teacher }\end{array}$ & 8 years & $\begin{array}{l}\text { Multi-trauma accident, PTSD. } \\
\text { Physical and mental fatigue; difficulty standing for } \\
\text { prolonged periods, difficulty sitting, being active in } \\
\text { the classroom or playground }\end{array}$ \\
\hline 10. Tony & Male, 28 years old & Carpenter & 5 years & $\begin{array}{l}\text { Herniated disc and other back issues. } \\
\text { Difficulty with physical activities like loading and } \\
\text { unloading lumber, framing, using heavy tools and } \\
\text { equipment. }\end{array}$ \\
\hline 11. Debbie & Female, 49 years old & $\begin{array}{l}\text { Lifeguard/Swim } \\
\text { coach }\end{array}$ & 14 years & $\begin{array}{l}\text { Arthritis and advanced degenerative disc disease. } \\
\text { Difficulty pulling, pushing, reaching and bending pool } \\
\text { equipment. Difficulty grasping \& manipulating small } \\
\text { objects }\end{array}$ \\
\hline 12. Reggie & Male, 54 years old & Athletic Director & 11 years & Low back pain, heart disease \\
\hline
\end{tabular}

$S D=0.44)$ and a moderate level of work engagement $(M=3.92, S D=0.77)$, organizational citizenship $(M=3.52, S D=0.21)$, and participation in job crafting behaviors $(M=3.61, S D=0.87)$. Daily diary reflections suggested no out-of-the ordinary events that may have skewed participant's responses, although three participants reported feeling stressed about handling multiple deadlines and job demands. The responses in the daily diary were reviewed to provide additional contextual information for the responses to the standardized questionnaires.

\subsection{Qualitative analysis of in-person interviews}

Twelve participants completed the in-person interviews and the Job Crafting Exercise ${ }^{\mathrm{TM}}$. Qualitative analysis of the interview data, collected before the intervention phase, revealed 19 first-order codes which were organized into themes. We identified four major themes as follows: 1) work limitations, 2) task adaptations, 3) collaborations and conflictmanagement, and 4) meaning in work. The themes revealed how participants constructed their daily work experience. Codes and themes are presented in Table 3 and are discussed in more detail below.

\subsubsection{Work limitations}

Participants discussed how their disability or health condition negatively affected their work performance, attendance at work, social interactions at work, and overall sense of self-worth at work. Work performance was negatively affected because participants did not have the stamina to endure an 8-hour work day, experienced pain during standing and heavy lifting, or had trouble bending and crouching. Jackie, an elementary school teacher who was return- 
Table 3

Codes and themes from in-depth interviews

\begin{tabular}{ll}
\hline First-order codes & Second-order themes \\
\hline Pain at work, mental distraction, stamina, stress related to health condition or disability & Work limitations \\
Collaboration, teamwork, positive workplace culture, unhealthy workplace culture & Collaboration and conflict management \\
$\begin{array}{l}\text { Strengths, passion, meaningful tasks, worker role identity } \\
\text { Adding job tasks, abandoning job tasks, modifying job tasks, autonomy, lack of autonomy, }\end{array}$ & Meaning in work \\
stress due to increased job demands & Job tadaptations \\
\hline
\end{tabular}

ing to full-time work after a multi-trauma accident, elaborated on her fatigue and lack of stamina:

“.... like last year, after once I returned back to school full time, that was the hardest for me because I just didn't have like the stamina to stand in front of the kids and teach them. Because, I would just get so tired, and I would need to sit a lot, and like now, I'm to the point where, ya know, I'm standing pretty much all day, and constantly running around the school - picking them up, and going here and there."

When asked about the most demanding aspects of her job, Jackie said:

“(P)robably just standing up in front of them and teaching and trying to be energetic. Since there's really not a lot of down time, just kind of, ya know, standing up and teaching, and kind of being on display all day, and contending with, ya know tying their shoes and ya know, putting out problems that I see during the day, yeah."

Lisa, a finance director experiencing chronic pain syndrome, reported that in the past she missed several days at work due to pain and for medical appointments. At the time of the interview, Lisa had negotiated an arrangement where she would work on Fridays, only if needed. Debbie, a swim instructor and lifeguard experiencing arthritis and advanced degenerative disc disease, reported working part-time to accommodate doctor's appointments. This allowed her to schedule doctor's appointments on Fridays. Participants reported experiencing physical and emotional stress on the job and that stress was sometimes aggravated by the presence of a disability or chronic condition. For Andy, an Associate Director of Athletic Communications, his ADHD limited his ability to focus and sustain attention on a task and that was causing stress.

“I feel like I can't sit there as long as I would hope to. In order to complete a task, I need to get up and get some water, or get up and go for a quick walk around the field or down to the mail room or something. Um, yes I do feel like it can stress me sometimes."

Physical stress was observed when participants were engaged in physically strenuous job tasks. Awkward or sedentary positions also contributed to physical stress on certain body parts. Emotional stress was observed in relation to meeting deadlines, taking on leadership roles without adequate clarity regarding role expectations, and negotiating inter-personal conflicts in the workplace. Participants noted that their disability or health condition amplified the experience of stress, as echoed in Tony's statement that "everything is directly related to the herniated disc."

\subsubsection{Task adaptations}

Prior to the intervention phase of this study, most participants were already adapting their job tasks to address their own work limitations and to meet the growing demands of their job. Participants engaged in this task crafting by collaborating on tasks, changing tasks to cope with adversity, or taking on additional responsibilities within their organization. Some participants took on additional responsibilities because they felt passionate about those tasks. Yet others took on additional tasks because no one else was available to do the job or because they felt that it was their moral obligation to meet the growing needs of the organization. Susan, who was the lead teacher in a school, remarked:

"So, I am a lead teacher, but I also feel like I am the person who parents deal with the most, um, I think I take on a lot of responsibility with my boss and being her administrator as well with sending emails answering the phones."

Expansion of current roles happened when workers were seeking personal enrichment and advancement in the workplace. Participants took pride and special interest in tasks that were directly related to their passion. Debbie, a part-time swim instructor, took special interest in creating unique aquatic fit- 
ness lessons that were not traditionally offered at the swim school. Delegating tasks, mentoring junior colleagues and re-structuring meetings were other ways in which participants choose to adapt their job tasks. In general, adapting tasks was possible when participants were able to exercise their autonomy. Mike, a disaster recovery manager, commented:

"Well, you know I mention uh some days I have choices, choices to make between going outside and doing physical labor with our mobile unit or staying indoors and uh, working, you know, on my computer or something similar to that nature. Um, I can make choices pretty much anytime I want. I can decide when I do certain tasks."

Although many participants adapted their job tasks or even expanded on their job roles, none of them considered cutting back on their job tasks. Bree, a customer service experience supervisor, however, said that she currently pushes through her tasks despite her back pain but was prepared to cut-back on her hours or quit her job entirely due to the stress of balancing her disability and her job tasks.

"Umm ... no, even though I do experience lower back pain, I still do like engage in the task that I have to do like I would never not carry the cambro (food storage container) back because my back hurts."

\subsubsection{Collaboration and conflict-management}

Collaboration in the workplace was manifested as offering and seeking assistance for specific job tasks. Participants offered assistance when the job task was within their area of expertise or was something that they were personally interested in. When participants were able to offer assistance to co-workers, they reported increased self-worth and improvements in team dynamics. Three participants welcomed the opportunity to mentor junior colleagues and offer assistance on technical aspects of their job. Tony, the carpenter, said:

"I'm slightly above a skilled laborer. I'm more of a teacher than anything. And I have to teach the younger guys to do what I've been taught to do."

When asked about giving and receiving help at work, Jackie, an elementary school teacher, said:

"If I ever have like a parent email where they're asking something specific, or ya know, I turn to like my teammates who are right there and ask them how, ya know, how they would respond back, what they would do in that situation. I also have a lot of, um, like support from our math and literacy specialist, so if I have a question on, ya know, a reading level or how to administer a certain test, I know I could rely on them to help me."

Seeking assistance, on the other hand, served to mitigate stressful situations related to upcoming deadlines, challenging new tasks, or work limitations. Lisa, the finance director who struggled with meeting multiple deadlines, commented:

"Things like, I asked Jon (co-worker) if he could help me, we only had a week to do a project, so, uh, I asked him for help with that. And, uh, usually we have a certain functionality that works ... I reach out to Jon to ask him to either show me or point me in the right direction to find documentation."

Inter-personal conflicts were observed when a new co-worker was introduced to the team or when co-workers had different work expectations. Ambiguity regarding job roles, especially in the absence of a supervisor, was cited as a reason for interpersonal conflict. Susan, the lead preschool teacher, avoided interacting with certain colleagues during the workday and redirected her social interactions to a different set of colleagues to avoid inter-personal conflict. Elijah described having to step outside of his typical business analyst role to diffuse a tense situation:

"Uh, one time when it happened, we've had a lot of change on our team, and we had like consultants coming in trying to teach us how we should be handling our work. So, um, one of my coworkers didn't see eye-to-eye with him and she started, um, talking about how much we could produce this better, uh, and they kind of just started butting heads and just arguing for $15 \mathrm{~min}$ utes or so. So, I just started asking questions that were related to what her concerns were, but without being so, uh, confrontational about it. And it just kind of suppressed the whole situation."

Tony, the carpenter, said the following about his co-workers:

"I mean they can be brutal too. They can be very pleasant and hilarious to very brutal and stressful. I, I mean [pause] there are, a, a couple of coworkers I wouldn't, I wouldn't bother trying to approach for help only because, I've not been 
able to get them to open up and it's just not worth my time".

Debbie, the swim instructor and lifeguard, discussed the importance of the overall workplace climate and culture and how, in the past, she felt hesitant taking a sick day.

"There was probably a-one time where I would, you know be like oh I wonder if I can, ask for a day off or something like that, but now I mean I just, I don't have any issues with talking about anything that's on, my mind."

Participants thus had some experience with relational crafting prior to participating in the job crafting intervention.

\subsubsection{Meaning in work}

Participants forged meaning in work when they were able to assist or connect with others at work (e.g., teach students, connect with customers or mentor colleagues) and when they were able to realize their passion and break out of their expected job role to accomplish something new. Andy, the associate director of athletic communications, tapped into his creative side to create infographics and reached out to coaches, two things that were not part of his job description. This also helped him with his ADHD and tendency to get bored with monotonous tasks.

"I've brought it upon myself to make more, uh, informative graphics for the different sports, such as calendars, uhm, other things. And I have been trying to implement meetings with coaches, uh, on my own so that they feel like they have a voice in the athletic department, uhm, other than theirs".

Lisa felt most accomplished when she was able to work with customers.

"Definitely working with customers. Um, making you know making and ensuring that they are satisfied with, um, their activities that our recovery center and that their when they accomplish their goals it leaves me satisfied that I've accomplished mine".

\subsection{Goal attainment scale and post-intervention measures}

Eleven participants completed the one-week implementation phase and the post-intervention daily diary. At the end of the intervention phase, scores for three of the four outcome measures were higher

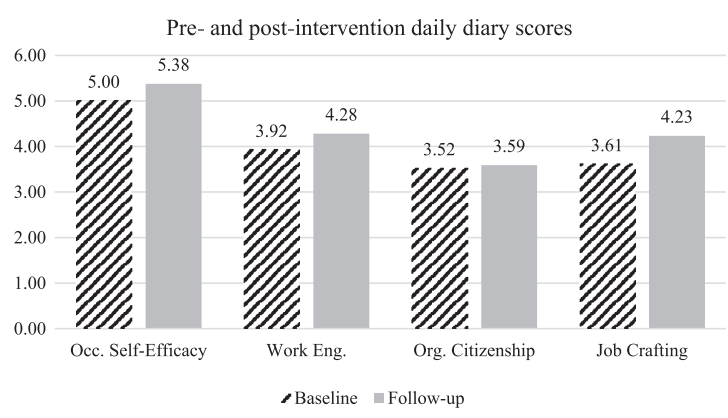

Fig. 2. Pre- and post-intervention daily diary scores. * Difference between pre- and post-intervention. Scores are significantly different at $p<0.05$.

than the pre-intervention scores. The average postintervention self-efficacy score was $5.28(S D=0.56)$; average work engagement score was $3.92(S D=$ 1.07), average organizational citizenship was 3.49 $(S D=0.43)$, and participation in job crafting behaviors was $4.13(S D=1.15)$.

\subsubsection{Comparison of pre- and post-intervention measures}

Post-intervention scores are compared graphically to pre-intervention scores in Fig. 2, showing increases over time in all scores.

To test for statistical differences between the fiveday average pre- and post-intervention scores for each participant, Wilcoxon signed-rank tests were used. Wilcoxon sign-rank tests were used due to the small sample size. Table 4 shows results for: (1) occupational self-efficacy, (2) work engagement, (3) organizational citizenship, and (4) job crafting.

There was a significant increase in post-intervention scores for occupational self-efficacy $(p=$ $0.023)$ and job crafting $(p=0.006)$. A large effect size was observed for occupational-self efficacy (Cohen's $d=0.98$ ) and for job crafting (Cohen's $d=0.90$ ), suggesting that the intervention produced clinically meaningful results. Although the scores for work engagement and organizational citizenship increased post-intervention, the differences were not statistically significant.

\subsubsection{Goal attainment scale}

Each participant set at least three goals to work on for the duration of the study. A total of 39 goals were set by the 12 participants. One participant dropped out after the goal setting process. All participants who continued in the study, accomplished at least one goal at the end of the study. Of the 34 goals set 
Table 4

Participant goals and goal accomplishment after the Job Crafting Exercise ${ }^{\text {TM }}$

\begin{tabular}{|c|c|c|c|c|}
\hline Name & Job title & Goals & Goal type & Goal status \\
\hline \multirow[t]{3}{*}{ Andy } & Associate Director of & 1. Take a 10-minute break before a long task & 1. Task crafting & 1. Goal accomplished \\
\hline & Athletic Communications & $\begin{array}{l}\text { 2. Identify } 2-3 \text { positive aspects of attending } \\
\text { meetings }\end{array}$ & 2. Cognitive crafting & $\begin{array}{l}\text { 2. Goal addressed but } \\
\text { not accomplished }\end{array}$ \\
\hline & & 3. Assign 1 job task to intern & 3. Task crafting & 3. Goal accomplished \\
\hline \multirow[t]{3}{*}{ Mike } & $\begin{array}{l}\text { Disaster Recovery } \\
\text { Coordinator }\end{array}$ & $\begin{array}{l}\text { 1. Engage in a meaningful conversation with } \\
\text { at least } 1 \text { customer }\end{array}$ & $\begin{array}{l}\text { 1. Cognitive \& } \\
\text { relational crafting }\end{array}$ & 1. Goal accomplished \\
\hline & & 2. Put more thought into planning events & 2. Cognitive crafting & 2. Goal accomplished \\
\hline & & 3. Create additional training documentation & 3. Task crafting & $\begin{array}{l}\text { 3. Goal addressed but } \\
\text { not accomplished }\end{array}$ \\
\hline \multirow[t]{5}{*}{ Molly } & Vegetable Farmer & 1. Cut stakes with left hand & 1. Task crafting & $\begin{array}{l}\text { N/A (participant } \\
\text { dropped out) }\end{array}$ \\
\hline & & $\begin{array}{l}\text { 2. Limit activities involving manual labor } \\
\text { especially, hand-manipulation to } 2 \text { hours a } \\
\text { day }\end{array}$ & 2. Task crafting & \\
\hline & & 3. Delegate all animal care tasks & 3. Task crafting & \\
\hline & & $\begin{array}{l}\text { 4. Delegate farming tasks to John and Anna } \\
\text { (co-workers) and focus on customer } \\
\text { service }\end{array}$ & $\begin{array}{l}\text { 4. Task and relational } \\
\text { crafting }\end{array}$ & \\
\hline & & $\begin{array}{l}\text { 5. Initiate conversation with XYZ } \\
\text { landowners to continue farming lease } \\
\text { (task not related to disability but cause of } \\
\text { significant work-related stress) }\end{array}$ & $\begin{array}{l}\text { 5. Relational and task } \\
\text { crafting }\end{array}$ & \\
\hline \multirow[t]{3}{*}{ Susan } & Lead Preschool Teacher & 1. Be assertive with co-worker & $\begin{array}{l}\text { 1. Relational and } \\
\text { cognitive crafting }\end{array}$ & 1. Goal accomplished \\
\hline & & 2. Delegate cleaning tables & $\begin{array}{l}\text { 2. Task and relational } \\
\text { crafting }\end{array}$ & 2. Goal accomplished \\
\hline & & 3. Take trash out at least once & 3. Task crafting & 3. Goal accomplished \\
\hline \multirow[t]{3}{*}{ Lisa } & Finance Director & $\begin{array}{l}\text { 1. Take two } 10 \text {-minute break walks } \\
\text { throughout the office }\end{array}$ & 1. Task crafting & $\begin{array}{l}\text { 1. Goal addressed but } \\
\text { not accomplished }\end{array}$ \\
\hline & & $\begin{array}{l}\text { 2. Eat lunch with co-worker or new hire once } \\
\text { a week }\end{array}$ & 2. Relational crafting & 2. Goal not addressed \\
\hline & & $\begin{array}{l}\text { 3. Discuss possibility of "standing hotel" } \\
\text { with boss }\end{array}$ & $\begin{array}{l}\text { 3. Relational and task } \\
\text { crafting }\end{array}$ & 3. Goal not addressed \\
\hline \multirow[t]{3}{*}{ Jada } & Customer Support and & 1. Spend more time with staff & 1. Relational crafting & 1. Goal accomplished \\
\hline & Services Specialist & 2. Collaborate more in drafting manual & $\begin{array}{l}\text { 2. Relational and task } \\
\text { crafting }\end{array}$ & 2. Goal accomplished \\
\hline & & 3. Walk to take breaks (for back pain) & 3. Task crafting & 3. Goal accomplished \\
\hline \multirow[t]{3}{*}{ Elijah } & Business Systems Analyst & $\begin{array}{l}\text { 1. Ask team member for insight regarding a } \\
\text { project }\end{array}$ & $\begin{array}{l}\text { 1. Relational and task } \\
\text { crafting }\end{array}$ & 1. Goal accomplished \\
\hline & & $\begin{array}{l}\text { 2. Collaborate more by setting up meeting } \\
\text { time in common area }\end{array}$ & $\begin{array}{l}\text { 2. Relational and task } \\
\text { crafting }\end{array}$ & $\begin{array}{l}\text { 2. Goal addressed but } \\
\text { not accomplished }\end{array}$ \\
\hline & & 3. Mentor new employee on testing issues & $\begin{array}{l}\text { 3. Relational and task } \\
\text { crafting }\end{array}$ & 3. Goal accomplished \\
\hline \multirow[t]{3}{*}{ Bree } & $\begin{array}{l}\text { Customer Service } \\
\text { Representative Supervisor }\end{array}$ & $\begin{array}{l}\text { 1. Communicate constructively with team } \\
\text { member }\end{array}$ & 1. Relational crafting & 1. Goal not addressed \\
\hline & & $\begin{array}{l}\text { 2. Communicate with co-worker who is not a } \\
\text { regular during non-peak hours }\end{array}$ & $\begin{array}{l}\text { 2. Relational and task } \\
\text { crafting }\end{array}$ & 2. Goal accomplished \\
\hline & & $\begin{array}{l}\text { 3. Delegate checking products to team } \\
\text { members }\end{array}$ & $\begin{array}{l}\text { 3. Relational and task } \\
\text { crafting }\end{array}$ & 3. Goal not addressed \\
\hline \multirow[t]{3}{*}{ Jackie } & Elementary school teacher & 1. Participate more during staff meeting & 1. Relational crafting & $\begin{array}{l}\text { 1. Goal addressed but } \\
\text { not accomplished }\end{array}$ \\
\hline & & 2. Ask colleagues/specialists for help & $\begin{array}{l}\text { 2. Relational and task } \\
\text { crafting }\end{array}$ & 2. Goal accomplished \\
\hline & & 3. Make more positive parent phone calls & 3. Relational crafting & $\begin{array}{l}\text { 3. Goal addressed but } \\
\text { not accomplished }\end{array}$ \\
\hline Tony & Carpenter & $\begin{array}{l}\text { 1. Be more mindful during communication } \\
\text { with co-workers and bosses at least once a } \\
\text { day (not directly related to disability but to } \\
\text { manage anger issues) }\end{array}$ & 1. Relational crafting & 1. Goal accomplished \\
\hline
\end{tabular}


Table 4

(Continued)

\begin{tabular}{|c|c|c|c|c|}
\hline Name & Job title & Goals & Goal type & Goal status \\
\hline & & $\begin{array}{l}\text { 2. Pay close attention to body position, not } \\
\text { lifting more than } 10 \mathrm{lbs}\end{array}$ & 2. Task crafting & $\begin{array}{l}\text { 2. Goal addressed but } \\
\text { not accomplished }\end{array}$ \\
\hline & & $\begin{array}{l}\text { 3. Manage time efficiently (prioritize tasks } \\
\text { and return from breaks on time) }\end{array}$ & 3. Task crafting & 3. Goal accomplished \\
\hline & & 4. Minimize repetitive lifting over $10 \mathrm{lbs}$. & 4. Task crafting & $\begin{array}{l}\text { 4. Goal addressed but } \\
\text { not accomplished }\end{array}$ \\
\hline \multirow[t]{3}{*}{ Debbie } & Lifeguard/ Swim coach & $\begin{array}{l}\text { 1. Implement lesson plan that allows her to } \\
\text { slide the lane lines for the hydro fitness } \\
\text { class }\end{array}$ & 1. Task crafting & 1. Goal accomplished \\
\hline & & $\begin{array}{l}\text { 2. Guard the pool by standing up for five } \\
\text { minutes of every hour }\end{array}$ & 2. Task crafting & 2. Goal accomplished \\
\hline & & $\begin{array}{l}\text { 3. Move the lane lines across the pool using a } \\
\text { string and by squatting for } 3 \text { out of } 5 \text { days }\end{array}$ & 3. Task crafting & 3. Goal accomplished \\
\hline \multirow[t]{3}{*}{ Reggie } & Athletic Director & $\begin{array}{l}\text { 1. Email first hour of the day to minimize } \\
\text { sitting }\end{array}$ & 1. Task crafting & 1. Goal accomplished \\
\hline & & 2. Clear clutter on the desk everyday & 2. Task crafting & $\begin{array}{l}\text { 2. Goal addressed but } \\
\text { not accomplished }\end{array}$ \\
\hline & & $\begin{array}{l}\text { 3. Answer phones standing up to take a } \\
\text { break from sitting }\end{array}$ & 3. Task crafting & 3. Goal accomplished \\
\hline
\end{tabular}

Table 5

Wilcoxon Signed Rank Test: Difference in median pre- and post-intervention measures $(n=11)$

\begin{tabular}{lcccc}
\hline & $\begin{array}{c}\text { Pre-intervention } \\
\mathrm{M}(\mathrm{SD})\end{array}$ & $\begin{array}{c}\text { Post-intervention } \\
\mathrm{M}(\mathrm{SD})\end{array}$ & Sig & $\begin{array}{c}\text { Cohen's d } \\
\text { (effect size) }\end{array}$ \\
\hline Occupational self efficacy & $5.00(0.44)$ & $5.38(0.33)$ & $0.023^{*}$ & 0.9 \\
Work engagement & $3.92(0.77)$ & $4.28(0.95)$ & 0.109 & - \\
Organizational citizenship & $3.52(0.21)$ & $3.59(0.3)$ & 0.593 & - \\
Job crafting & $3.61(0.87)$ & $4.23(0.9)$ & $0.006^{* *}$ & 0.98 \\
\hline
\end{tabular}

${ }^{*} p<0.05,{ }^{* *} p<0.01$.

by participants who completed the study, 21 goals (62\%) were accomplished; nine goals (24\%) were addressed but not accomplished, and 4 (12\%) were not addressed. Participant goals and goal accomplishment status are presented in Table 5.

Participants were asked how the Job Crafting Exercise $^{\mathrm{TM}}$ helped them problem solve challenges with their job tasks and roles, redefine social interactions and realize meaning associated with their work. Participants elaborated on how they were able to prioritize among various tasks, focus on the most important job demands, delegate tasks when necessary, and leverage their strengths in the workplace. One participant remarked: "Seeing my weaknesses written down helped me deal with them in the real world and notice them." With regards to relational crafting, participants noted that the Job Crafting Exercise $^{\mathrm{TM}}$ helped them establish more social connections with colleagues and customers, as reflected in one participant's comment that participation in the exercise, "gave me courage to utilize social time as a time to get to know co-workers." Finally, when asked about the meaning associated with their work, participants acknowledged a heightened sense of awareness regarding their contribution to their organization and their own sense of self-worth that was tied to their jobs. Lisa reported feeling accomplished when she tackled a difficult hydro-fitness lesson, despite her back issues. Reggie, who was dealing with chronic low back pain, was proud that he followed through with his goal of answering phone calls standing, to break up the monotony of sitting down. He stated that standing while answering calls was "becoming more a habit" towards the end of the intervention period. Jackie reported that the Job Crafting Exercise $^{\mathrm{TM}}$ made her and her co-workers value her contribution; she said, "I felt good about teaching my class today because I originally was not going to be at work today and they were going to have to do the class on their own. They (co-workers) appreciated that."

\section{Discussion}

The purpose of this pilot study was to test the effectiveness of using job crafting as a coaching-based OT 
intervention strategy to improve self-efficacy, work engagement, organizational citizenship and job crafting behaviors of workers with work limitations and disabilities. The results from this pilot study yielded several research findings and highlighted some areas in need of further research. First, participants, all of whom had a health condition that impacted their work, reported high levels of occupational selfefficacy and moderate levels of job crafting, work engagement, and organizational citizenship prior to participating in the intervention.

Second, despite having high initial levels of occupational self-efficacy, study participants experienced statistically significant increases in occupational selfefficacy after the intervention. Study participants also experienced statistically significant increases in job crafting behaviors, from a moderate level of job crafting at baseline. The coaching-based job crafting intervention, even when used for a relatively short time as in the study described here, was effective in increasing average levels of occupational self-efficacy across the five-day post-intervention period. Self-efficacy has been shown to be important not only for career success [55] but also for long-term career trajectories [27], two areas in need of improvement for workers with work limitations and disabilities. Prior research $[29,32,56]$ has suggested that levels of self-efficacy are positively associated with job performance and crafting behaviors. Although an increasing trend was observed in the work engagement and organizational citizenship scales, the change was not statistically significant. Our findings are consistent with previous research that demonstrated that among health professionals and teachers, job crafting interventions resulted in increased work engagement $[57,58]$.

Third, findings from the qualitative phase of our study revealed that participants engaged in job crafting by modifying job tasks and managing conflicts and collaborating with co-workers. Task crafting offered participants an opportunity to expand current job roles and cope with difficult situations by modifying the scope of job tasks. Development focused job crafting is a process by which employees align job tasks to their own personal resources and strengths. Similarly, by slightly altering the nature and scope of tasks, study participants were able to forge new relationships and carve out who they would interact with in the workplace. Relational crafting often happened in the context of job tasks when workers intentionally avoided or sought our new connections while engaging in various job tasks. Relational crafting also took the form of mentorship and occurred in conjunction with role expansion. To our knowledge, this is one of the first few studies on how individuals with work limitations used job crafting as an intervention strategy to improve work engagement.

Job crafting is distinct from traditional approaches to achieving person-job task fit such as using workplace accommodations and assistive technology because it involves using a top-down approach to change the nature of job tasks to meet an individual need. In other words, rather than addressing limitations through the use of workplace accommodations, job crafting unfolds as a strengths-based approach, where employees work towards leveraging or expanding on their strengths and passions. The resulting change in job roles may benefit the individual and/or the organization. Previous research [59] has shown that, in general, although Americans with disabilities engage less in relational and task crafting, they are able to re-frame their work situations to forge meaning and value through work.

Occupational therapists help clients realize their fullest potential in life, including work roles. For workers with work limitations and disabilities, finding a job or returning to work after a disability or injury is necessary but insufficient to achieve long-term self-sufficiency. In order to maximize the benefits of employment, people with disabilities must have opportunities to thrive and flourish in their jobs and prolong their job tenure. The use of coachingbased OT interventions to improve work outcomes is relatively new. Our use of a coaching-based, job crafting intervention strategy resulted in improvements in self-efficacy among workers with work limitations and disabilities. These results are promising in expanding the scope of OT and demonstrating the distinct value of OT by helping clients achieve greater engagement and satisfaction at work.

For workers with limitations and disabilities, longterm career success depends on how well they address both disability and non-disability related challenges. While traditional deficits-based models may be limited to identifying certain functional and job performance limitations, the job crafting helped participants identify and address non-disability related stressors as well, such as anger issues or conflicts of interest with other business partners. Addressing these factors can help achieve a holistic approach to address challenges in the workplace. Job crafting as an intervention strategy is distinct from other interventions that promote work readiness or work skills training program because (1) here the changes are 
initiated by the workers themselves and the clinician plays the role of a facilitator and (2) the intervention occurs within the natural workplace context.

When used repeatedly, over the long-term, job crafting may have the ability to improve job retention for individuals with work limitations and disabilities, an area of concern not only to employees themselves but also to employers of persons with disabilities and the public and private systems that engage with disconnected workers with disabilities. Interventions that help people with disabilities stay on the job can indirectly impact unemployment rates by reducing job turnovers and prolonging labor force participation. Findings from this research can add to the growing body of evidence that supports programs and policies that advance career goals of people with disabilities beyond job placement.

\section{Methodological considerations/limitations}

This study has several limitations. First, the small sample size limits the generalizability of the results. Second, the post-intervention data collection was restricted to five days. Many participants felt that the timeline was insufficient to make actual changes at their jobs even though their goals were broken down into daily actionable steps. A longer time frame may be needed to see impacts of job crafting on work engagement and organizational citizenship. Extended data collection was beyond the scope of this pilot study and is planned for a future study. Third, graduate students who worked with participants observed that many participants were reluctant to acknowledge that their impairment or health condition negatively impacted their work performance and work-related wellbeing. Replicating this study with a larger sample will allow us to further explore this phenomenon.

Last, participants felt burdened by having to complete the online diary every day. However, some participants remarked that the daily reminder of their goals helped them stay motivated to make actual changes at work. Future research can study the relative costs and benefits of daily versus weekly completion of the online diary.

\section{Conclusion}

Despite the study design limitations, job crafting has the potential to be used as a strengths-based, coaching intervention to improve the self-efficacy of individuals with work limitations, disabilities, and/or chronic conditions. Job crafting provides a holistic framework to address both disability and nondisability related challenges at work. Job crafting is a promising tool that occupational therapists can use to help clients realize their fullest potential at work.

\section{Acknowledgments}

This project was funded the University of New Hampshire's College of Health and Human Services. We are grateful for the assistance from the UNH Occupational Therapy graduate students, class of 2017.

\section{Conflict of interest}

The authors have no conflicts of interests to declare.

\section{References}

[1] Wrzesniewski A, Dutton JE. Crafting a job: Revisioning employees as active crafters of their work. Academy of Management Review. 2001;26(2):179-201.

[2] Berg JM, Dutton JE, Wrzesniewski A. Job crafting and meaningful work. Purpose and Meaning in the Workplace. 2013;81-104.

[3] Sundar V, O’Neill J, Houtenville AJ, Phillips KG, Keirns T, Smith A, et al. Striving to work and overcoming barriers: Employment strategies and successes of people with disabilities. Journal of Vocational Rehabilitation. 2018;48(1): 93-109.

[4] Allaire SH, Li W, LaValley MP. Reduction of job loss in persons with rheumatic diseases receiving vocational rehabilitation: A randomized controlled trial. Arthritis \& Rheumatism. 2003;48(11):3212-8.

[5] Lock S, Jordan L, Bryan K, Maxim J. Work after stroke: Focusing on barriers and enablers. Disability \& Society. 2005;20(1):33-47.

[6] Noonan BM, Gallor SM, Hensler-McGinnis NF, Fassinger RE, Wang S, Goodman J. Challenge and success: A qualitative study of the career development of highly achieving women with physical and sensory disabilities. Journal of Counseling Psychology. 2004;51(1):68-80.

[7] Kulkarni M, Gopakumar K. Career management strategies of people with disabilities. Human Resource Management. 2014;53(3):445-66.

[8] Wehman P, Brooke V, Brooke AM, Ham W, Schall C, McDonough J, Lau S, Seward H, Avellone L. Employment for adults with autism spectrum disorders: A retrospective review of a customized employment approach. Research in Developmental Disabilities. 2016;53(1):61-72. 
[9] Wehman P, Lau S, Molinelli A, Brooke V, Thompson K, Moore C, West M. Supported employment for young adults with autism spectrum disorder: Preliminary data. Research and Practice for Persons with Severe Disabilities. 2012; 37(3):160-9.

[10] Wright JH, Mishkind M, Eells TD, Chan SR. Computerassisted cognitive-behavior therapy and mobile apps for depression and anxiety. Current Psychiatry Reports. 2019; 21(7):62.

[11] Li C, Xu D, Hu M, Tan Y, Zhang P, Li G, Chen L. A systematic review and meta-analysis of randomized controlled trials of cognitive behavior therapy for patients with diabetes and depression. Journal of Psychosomatic Research. 2017;95(1):44-54.

[12] Spinhoven P, Klein N, Kennis M, Cramer AO, Siegle G, Cuijpers P, Ormel J, Hollon SD, Bockting CL. The effects of cognitive-behavior therapy for depression on repetitive negative thinking: A meta-analysis. Behaviour Research and Therapy. 2018;106(1):71-85.

[13] Soeker MS. The experiences of occupational therapists regarding the use of the Model of Occupational Self Efficacy. Work. 2016;55(3):689-701.

[14] Soeker S. A pilot study on the operationalization of the Model of Occupational Self Efficacy: A model for the reintegration of persons with brain injuries to their worker roles. Work. 2016;53(3):523-34.

[15] Rojewski JW. Career assessment for adolescents with mild disabilities: Critical concerns for transition planning. Career Development for Exceptional Individuals. 2002;25(1): 73-95.

[16] Baldridge DC, Kulkarni M. The shaping of sustainable careers post hearing loss: Toward greater understanding of adult onset disability, disability identity, and career transitions. Human Relations. 2017;70(10):1217-36.

[17] Szymanski EM, Enright MS, Hershenson DB, Ettinger JM. Career development theories, constructs, and research: Implications for people with disabilities. In: Szymanski EM, Parker RM, editors. Work and disability: Issues and strategies in career development and job placement. $2^{\text {nd }}$ ed. Austin (TX): PRO-ED; 2003. p. 91-153.

[18] Waghorn G, Chant D, King R. Work-related self-efficacy among community residents with psychiatric disabilities. Psychiatric Rehabilitation Journal. 2005;29(2):105-13.

[19] Bandura A. Social foundations of thought and action. Englewood Cliffs (NJ): Prentice Hall; 1986.

[20] Tims M, Bakker AB, Derks D. Development and validation of the job crafting scale. Journal of Vocational Behavior. 2012;80(1):173-86.

[21] Bakker AB, Tims M, Derks D. Proactive personality and job performance: The role of job crafting and work engagement. Human Relations. 2012;65(10):1359-78.

[22] Schaufeli WB, Salanova M, González-Romá V, Bakker $\mathrm{AB}$. The measurement of engagement and burnout: A two sample confirmatory factor analytic approach. Journal of Happiness Studies. 2002;3(1):71-92.

[23] De Beer LT, Tims M, Bakker AB. Job crafting and its impact on work engagement and job satisfaction in mining and manufacturing. South African Journal of Economic and Management Sciences. 2016;19(3):400-12.

[24] Tims M, Bakker AB. Job crafting: Towards a new model of individual job redesign. SA Journal of Industrial Psychology. 2010;36(2):1-9.

[25] Berg JM, Grant AM, Johnson V. When callings are calling: Crafting work and leisure in pursuit of unanswered occupational callings. Organization Science. 2010;21(5):973-94.
[26] Leana C, Appelbaum E, Shevchuk I. Work process and quality of care in early childhood education: The role of job crafting. Academy of Management Journal. 2009;52(6): 1169-92.

[27] Wrzesniewski A, Dutton JE, Debebe G. Interpersonal sensemaking and the meaning of work. Research in Organizational Behavior. 2003;25:93-135.

[28] Van den Heuvel M, Demerouti E, Peeters MC. The job crafting intervention: Effects on job resources, self-efficacy, and affective well-being. Journal of Occupational and Organizational Psychology. 2015;88(3):511-32.

[29] van Wingerden J, Bakker AB, Derks D. The longitudinal impact of a job crafting intervention. European Journal of Work and Organizational Psychology. 2017;26(1):107-19.

[30] Bakker AB, Rodríguez-Muñoz A, Sanz Vergel AI. Modelling job crafting behaviours: Implications for work engagement. Human Relations. 2016;69(1):169-89.

[31] Kooij DTAM, Tims M, Kanfer R. Successful aging at work: The role of job crafting. In: Bal PM, Kooij DTAM, Rousseau DM, editors. Aging workers and the employee-employer relationship. Cham: Springer International Publishing; 2015. pp. 145-161.

[32] Van Wingerden J, Derks D, Bakker AB. The impact of personal resources and job crafting interventions on work engagement and performance. Human Resource Management. 2017;56(1):51-67.

[33] Amini D. Occupational therapy interventions for workrelated injuries and conditions of the forearm, wrist, and hand: A systematic review. American Journal of Occupational Therapy. 2011;65(1):29-36.

[34] Bade S, Eckert J. Occupational therapists' critical value in work rehabilitation and ergonomics. Work. 2008;31(1): 101-11.

[35] Désiron HA, de Rijk A, Van Hoof E, et al. Occupational therapy and return to work: A systematic literature review. BMC Public Health. 2011;11(1):615.

[36] Graham F, Rodger S, Ziviani J. Coaching parents to enable children's participation: An approach for working with parents and their children. Australian Occupational Therapy Journal. 2009;56(1):16-23.

[37] Kessler D, Ineza I, Patel H, Phillips M, Jehanne-Dubouoz C. Occupational Performance Coaching adapted for stroke survivors (OPC-Stroke): A feasibility evaluation. Physical \& Occupational Therapy in Geriatrics. 2014;32(1):42-57.

[38] Graham F, Rodger S. Occupational performance coaching: Enabling parents' and children's occupational performance. In:, Rodger, S editor. Occupation-centred practice with children: A practical guide for occupational therapists. West Sussex (UK): Wiley-Blackwell; 2010. pp. 203-226.

[39] Kessler D, Graham F. The use of coaching in occupational therapy: An integrative review. Australian Occupational Therapy Journal. 2015;62(3):160-76.

[40] Theeboom T, Beersma B, van Vianen AE. Does coaching work? A meta-analysis on the effects of coaching on individual level outcomes in an organizational context. The Journal of Positive Psychology. 2014;9(1):1-8.

[41] Foster L, Dunn W, Lawson LM. Coaching mothers of children with autism: A qualitative study for occupational therapy practice. Physical \& Occupational Therapy in Pediatrics. 2013;33(2):253-63.

[42] Creswell JW, Clark VLP. Designing and conducting mixed methods research. $5^{\text {th }}$ ed. Thousand Oaks (CA): Sage publications; 2018.

[43] Schyns B, Von Collani G. A new occupational selfefficacy scale and its relation to personality constructs and 
organizational variables. European Journal of Work and Organizational Psychology. 2002;11(2):219-41.

[44] Schaufeli W, Bakker A. UWES-Utrecht work engagement scale: Test manual. Unpublished Manuscript: Department of Psychology, Utrecht University. 2004. [cited 2019 May 23]. Available from https://www.wilmarschaufeli.nl/ publications/Schaufeli/Test\%20Manuals/Test_manual_UW ES_English.pdf

[45] Williams LJ, Anderson SE. Job satisfaction and organizational commitment as predictors of organizational citizenship and in-role behaviors. Journal of Management. 1991;17(3):601-17.

[46] Slemp GR, Vella-Brodrick DA. The Job Crafting Questionnaire: A new scale to measure the extent to which employees engage in job crafting. International Journal of Wellbeing. 2013;3(2):126-46.

[47] Tims M, B. Bakker A, Derks D. Daily job crafting and the self-efficacy-performance relationship. Journal of Managerial Psychology. 2014;29(5):490-507.

[48] Rodríguez-Muñoz A, Sanz-Vergel AI, Demerouti E, Bakker AB. Engaged at work and happy at home: A spillovercrossover model. Journal of Happiness Studies. 2014; 15(2):271-83.

[49] Bakker AB, Oerlemans WG. Daily job crafting and momentary work engagement: A self-determination and self-regulation perspective. Journal of Vocational Behavior. 2019;112:417-30.

[50] Berg JM, Dutton JE, Wrzesniewski A. Job Crafting Exercise $^{\mathrm{TM}}$. Ann Arbor, MI: Regents of the University of Michigan; 2008 [cited 2019 June 2]. Available from: http:// www.jobcrafting.org.
[51] Kiresuk TJ, Sherman RE. Goal attainment scaling: A general method for evaluating comprehensive community mental health programs. Community Mental Health Journal. 1968;4(6):443-53.

[52] Braun V, Clarke V. Using thematic analysis in psychology. Qualitative research in psychology. 2006;3(2):77-101.

[53] Portney LG, Watkins MP, Foundations of clinical research: applications to practice (Vol. 892). 2009. Upper Saddle River, NJ: Pearson/Prentice Hall.

[54] Stajkovic AD, Luthans F. Self-efficacy and work-related performance: A meta-analysis. Psychological Bulletin. 1998;124(2):240.

[55] Waghorn GR, Chant DC, King R. Work-related subjective experiences, work-related self-efficacy, and career learning among people with psychiatric disabilities. American Journal of Psychiatric Rehabilitation. 2007;10(4):275-300.

[56] Tims M, Bakker AB, Derks D. The impact of job crafting on job demands, job resources, and well-being. Journal of Occupational Health Psychology. 2013;18(2):230-40.

[57] Van Wingerden J, Bakker AB, Derks D. Fostering employee well-being via a job crafting intervention. Journal of Vocational Behavior. 2017;100:164-74.

[58] Gordon HJ, Demerouti E, Le Blanc PM, Bakker AB, Bipp $T$, Verhagen MA. Individual job redesign: Job crafting interventions in healthcare. Journal of Vocational Behavior. 2018;104:98-14.

[59] Brucker DL, Sundar V. 2020. Job Crafting Among American Workers with Disabilities. Journal of Occupational Rehabilitation. https://doi.org/10.1007/s10926-020-09889-9 